\title{
LA PROTECCIÓN DEL TITULAR REGISTRAL MEDIANTE LA ACCIÓN DEL ARTÍCULO 41 DE LA LEY HIPOTECARIA EN EL SISTEMA INMOBILIARIO REGISTRAL ESPAÑOL
}

THE TITLE HOLDER'S PROTECTION THROUGH ARTICLE 41

ACTION OF THE MORTGAGE STATUTE IN THE SPANISH LAND REGISTERED SYSTEM

LA PROTECTION DU TITULAIRE DU REGISTRE FONCIER

PARMIS L'ACTION DE L'ARTICLE 41 DE LA LOI DE L'HYPOTHÈQUE DANS LE

SYSTÈME IMMOBILIÈRE DU REGISTRE FONCIER ESPAGNOL

María Victoria Mayor del Hoyo*

\section{La aCción del arTículo 41 de la Ley Hipotecaria \\ EN EL SISTEMA INMOBILIARIO REGISTRAL ESPAÑOL: UN INSTRUMENTO \\ DE PROTECCIÓN DEL TITULAR REGISTRAL. ANTECEDENTES Y REGULACIÓN ACTUAL}

El Registro de la propiedad nace en el sistema español con la pretensión de constituir una suerte de mapa jurídico de la propiedad de cada finca y los gravámenes que pesan sobre ella. Como regla general, la inscripción en el Registro no es constitutiva y los posibles vicios del acto transmisivo o constitutivo no quedan subsanados con la inscripción, por lo que el Registro no es infalible. No obstante, se puede afirmar que es tendencialmente exacto, ya que el sistema trata de proporcionar una información lo más certera posible, ofreciendo una razonable seguridad de que sus manifestaciones son verdaderas y reales.

Esta tendencia a la exactitud registral o presunción de veracidad del Registro de la Propiedad produce consecuencias respecto a terceros adquirentes, dando lugar al principio de fe pública registral. En virtud de este principio, quien adquiere e inscribe un derecho real sobre un bien inmueble previamente inscrito en el Registro es protegido en su adquisición, aun cuando haya inexactitud en el Registro -art. 34 de la Ley Hipotecaria-. Existe en este caso una presunción iuris et de iure de exactitud.

Pero la presunción de exactitud del Registro actúa también en favor del titular inscrito, si bien, en este caso, con carácter iuris tantum, dando lugar entonces al llamado principio de legitimación registral, cuya formulación legal resulta de la combinación de los artículos 1.3, 38.1 y 97 de la Ley Hipotecaria, y conforme al

* Abogada. Doctora en Derecho. Profesora Titular de Derecho Civil Facultad de Derecho de la Universidad de Zaragoza, España. Correspondencia a: Correo electrónico mvmayor@unizar.es. 
cual, mientras no se demuestre la inexactitud de lo inscrito, el titular registral debe ser considerado en cualquier lugar y tiempo y por cualquier persona como titular verdadero o real. Pues bien, una de las formas en que se manifiesta la protección al propio titular registral, que deriva de la presunción de exactitud que proclaman los citados preceptos, es la acción real registral, regulada, fundamentalmente, en el artículo 41 de la Ley Hipotecaria.

Se trata de una acción de efectuación posesoria que puede ejercitar el titular inscrito contra quien se oponga o perturbe el ejercicio del derecho que publique el asiento. Establece, en concreto, el artículo 41: "Las acciones reales procedentes de los derechos inscritos podrán ejercitarse a través del juicio verbal regulado en la Ley de Enjuiciamiento Civil, contra quienes, sin titulo inscrito, se opongan a aquellos derechos o perturben su ejercicio. Estas acciones, basadas en la legitimación registral que reconoce el artículo 38, exigirán siempre que por certificación del registrador se acredite la vigencia, sin contradicción alguna, del asiento correspondiente”.

Fue, precisamente, la primera versión de este precepto en la Ley Hipotecaria de 1909, una de las primeras manifestaciones de la protección al titular registral o de la también llamada eficacia defensiva de la inscripción registral.

Y es que la Ley Hipotecaria de 1861 tuvo como idea central la ya mencionada protección de terceros. El Registro limitó inicialmente su eficacia a la protección al adquirente. El hecho de tener inscrita su titularidad no otorgaba al titular ninguna ayuda apreciable en la vida diaria. De ahí que la aludida reforma de 1909 constituyese un fuerte avance hacia la eficacia defensiva. Si antes de ella, el titular registral que era privado o perturbado en la posesión de su derecho inscrito debía acudir, igual que el propietario no inscrito, a la acción reivindicatoria o al interdicto, tras ella, la posición del titular tabular adquiría fuerza, al autorizársele para obtener esa posesión por un procedimiento especial.

Pero ese inicial artículo 41 introducido en la Ley Hipotecaria en 1909, y matizado por el Reglamento de 1915 en su artículo 100, fue objeto de importantes críticas, destacando la referida al carácter iuris et de iure de la presunción de titularidad, por el que, tras algunas dudas, pareció inclinarse el Tribunal Supremo. Dicho carácter otorgaba una protección absoluta al titular registral, que podía obtener el lanzamiento inmediato de cualquier detentador sin posibilidad de discusión.

Ello fue considerado excesivo y se procedió a modificar el artículo 41 a través del Real decreto-ley de 1927. Pero, pese a la buena intención del legislador y el atractivo que implicaba la reforma al presentarse como un modo de suavizar los excesos de la anterior norma, no gozó de éxito. Enseguida se destacó su redacción oscura, las dificultades interpretativas que ocasionaba, sus deficiencias técnicas, etc., y ello hizo surgir la idea de una nueva reforma, que se produjo en 1944-1946, momento en el que se completó el artículo 41 con los artículos 137 y 138 del Reglamento Hipotecario de 1947.

Esta última regulación de 1946 ha sido la que ha regido la acción real registral hasta la Ley de Enjuiciamiento Civil de 2000, momento en el que la pluralidad de 
cauces procedimentales previstos, tanto en la Ley de Enjuiciamiento Civil anterior, como en otras normas especiales, hizo que el legislador se fijara como objetivo la simplificación procedimental y decidiera la modificación del artículo 41 de la Ley Hipotecaria. La reforma del año 2000, que, con alguna variante, reduce el artículo 41 al párrafo primero, reconduce, efectivamente, la sustanciación de la acción real registral al cauce del juicio verbal, pero introduce tantas especialidades en éste que, en realidad, el procedimiento resultante no difiere en lo esencial del regulado en el anterior artículo 41 de la Ley Hipotecaria. Puede decirse, en líneas generales, que la regulación suprimida de la legislación hipotecaria se halla ahora dispersa en el Título III del Libro Segundo de la Ley de Enjuiciamiento Civil. Dicho traslado ha arrastrado consigo la regulación de cuestiones civiles, mezcladas con el procedimiento, que, en algunos casos, ayuda a aclarar la institución. Queda, para acabar con esta reforma, observar que la nueva Ley de Enjuiciamiento Civil afecta también a los citados artículos 137 y 138 del Reglamento Hipotecario, derogándolos en aquello que no sea conforme con la nueva regulación.

\section{NatURALEZA y CARACTERES DE LA ACCIÓN}

Antes de descender a otras cuestiones más concretas sobre el régimen de la acción real registral, procede detenerse en un aspecto de tinte, quizás, más abstracto, como el de su naturaleza y carácter, para ir construyendo la estructura interna que nos permita poder ir entendiendo esta institución para llegar a contemplarla finalmente en su totalidad.

En primer lugar, hay que aludir a la autonomía de la acción real registral; cuestión esta sobre la que, debo advertir, no existe unanimidad. Si bien hay voces que defienden que el artículo 41 de la Ley Hipotecaria se ha limitado a establecer simplemente un procedimiento sumario para el ejercicio de las acciones reales derivadas de los derechos inscritos; sin embargo, en mi opinión -y en opinión, puede decirse que, de la mayoría de la doctrina- este artículo da lugar a una acción diferente de las acciones propias de los titulares civiles, es decir, crea una acción de naturaleza especial y autónoma.

Ciertamente, a la primera conclusión puede llegarse si nos dejamos llevar sin más por la literalidad de una desafortunada redacción de la ley en su artículo 41, que comienza diciendo: "Las acciones reales procedentes de los derechos inscritos podrán ejercitarse a través del juicio verbal...". Pero, si nos alejamos de la superficie de la literalidad, y llevamos a cabo un análisis reflexivo partiendo de la esencia, llegamos a la conclusión de que lo que hay es una acción nueva y distinta. De hecho, si bien el legislador del 2000 mantiene, probablemente por inercia, la referida desafortunada redacción del comienzo del artículo 41, procedente de la reforma de 1946, sin embargo, cuando introduce ex novo en la Ley de Enjuiciamiento Civil este supuesto, sí utiliza ya una expresión más acorde con la realidad y que no desorienta al intérprete. De esta forma, el artículo 250.1. $7^{\circ}$ de esta ley, al enumerar las demandas que se decidirán en juicio verbal, alude a "las que, instadas 
por los titulares de derechos reales inscritos en el Registro de la Propiedad, demanden la efectividad de esos derechos...".

El punto de partida reside en la causa de esta acción: la inscripción en el Registro de la Propiedad. No deriva la acción del derecho real, ni de una presunción posesoria, sino de la inscripción registral, y ello da la clave de lo demás. Tiene esta acción quien ha inscrito su derecho real y por el mero hecho de haberlo inscrito. En la base de esta idea se encuentra la presunción de exactitud del Registro. Se trata de una presunción, como se sabe, iuris tantum, lo que quiere decir que, si bien sirve para justificar la legitimación específica que el artículo 41 confiere al titular tabular, no da lugar a una ficción que identifique inscripción con existencia auténtica del derecho real y con su posesión. Lo que significa que el hecho de legitimarse al titular inscribiente, no hace derivar la acción del derecho real o de una presunta posesión, que podrán existir o no, sino, simplemente, de la inscripción.

Si la acción reivindicatoria es una pretensión real de restitución del propietario no poseedor frente al poseedor no propietario, que forma parte del contenido del derecho de propiedad, o que nace de él; la acción del artículo 41 es una acción real de efectuación posesoria que, ni forma parte del contenido del derecho de propiedad, ni nace de él, sino que deriva, por disposición de la ley, del hecho de la inscripción, con total independencia de la existencia real de dicho derecho de propiedad.

Ello tiene sus consecuencias, mientras que la acción reivindicatoria exige como requisito la concurrencia y prueba del título de dominio del actor, para interponer la acción real registral únicamente hay que acreditar la inscripción.

Por otro lado, mientras que la acción reivindicatoria permite al demandado la plena discusión del dominio objeto de litigio, con la acción real registral no se dilucida, ni cabe discutir de modo alguno, si el titular inscrito es o no propietario, sino únicamente si es titular registral y si el derecho publicado tiene o no la posibilidad de exigir al demandado la reintegración posesoria. Ello significa que, que mediante el ejercicio de la acción reivindicatoria se hace concordar la situación de hecho con la realidad jurídica, mediante el ejercicio de la acción real registral se hace concordar la situación de hecho con la situación tabular, coincida o no ésta con la realidad jurídica. Y que la definitiva concordancia entre la situación de hecho, el Registro y la realidad jurídica, queda para el juicio ordinario que corresponda.

Además, y enlazando con esto último, mientras que la acción reivindicatoria, al permitir la plena discusión del dominio, se dirige a producir un estado jurídico definitivo, es decir, una sentencia con el valor de cosa juzgada, la acción real registral, al excluir esa discusión, se limita a crear una situación jurídica provisional: da lugar a una efectividad rápida meramente provisional del derecho inscrito, susceptible de ser revisada en el juicio declarativo correspondiente; no tiene, en definitiva, la sentencia resultante el valor de cosa juzgada.

Determinada la naturaleza autónoma de la acción real registral, corresponde hacer frente a la controvertida cuestión del carácter posesorio o petitorio que ha de atribuírsele a la misma. 
En mi opinión, hay que comenzar por desechar el carácter posesorio de la acción real registral. Y es que, si bien el hecho de que esta acción tenga por objeto una efectuación posesoria, unido a la provisionalidad de la sentencia que pone fin al procedimiento, podría llevar a asimilarla con los llamados interdictos, no es la posesoria su naturaleza. Para llegar a esta conclusión, conviene recordar que las acciones posesorias se llaman así no por estar destinadas a recuperar la posesión, sino por fundarse en ella. Se trata de acciones que defienden el "derecho a seguir teniendo", esto es, el ius possessionis, que deriva del hecho posesorio en sí. Y la acción real registral no se basa en la posesión del actor, ni siquiera en una presunción de posesión, sino en la inscripción en el Registro del derecho real. Con ella lo que se busca es adaptar la situación de hecho a la registral, es decir, la efectividad de la situación posesoria que corresponde al contenido del derecho publicado, con independencia de que el actor tuviera o no previamente la posesión, en cuanto que no se trata de restaurarle la posesión que tuvo y perdió.

Rechazado el carácter posesorio, se presenta como naturaleza alternativa la petitoria, pero creo que debe ser matizada, ya que si esta acción no forma parte, ni nace del derecho de propiedad, sino que se funda en la inscripción, ello significa que el carácter petitorio no deriva del derecho real que publica el Registro y debe excluirse la calificación de juicio de la propiedad en un sentido estricto. Tendremos que acompañar al carácter vindicatorio del calificativo "especial", al derivar de la titularidad sí, pero registral.

\section{CONTENido DE LA ACCIÓN}

Continuando con el estudio de la acción real registral, me referiré al contenido de la acción, aunque he tenido ocasión de adelantar en cierto modo una idea general, merece la pena una mención separada para dejar sentados algunos puntos de interés.

Aun estando ante una acción con naturaleza propia y autónoma, puede existir la tentación de buscar su contenido en otras acciones reales, lo cual no parece necesario, ni siquiera práctico, y aún menos hacerlo depender de ellas. Es cierto que el contenido de la acción real registral en ocasiones se acerca mucho al de otras acciones, pero no tiene por qué ser siempre así, dado que su propia naturaleza le infunde matices que pueden alejarla en determinados aspectos de ellas. Por ello, creo que, mejor que encorsetar su contenido, que puede introducir limitaciones innecesarias, hay que destacar la existencia de un contenido propio, que queda delimitado o dibujado con trazos basados en la finalidad perseguida con la acción, donde caben muchas posibilidades de actuación en las que se concreta, dependiendo del derecho real en cuestión.

Así, efectuando una abstracción del común denominador o esencia de todas las posibilidades de ejercicio de esta acción, puede decirse que el contenido de la demanda es una pretensión de integración o efectuación posesoria, en el sentido de hacer efectivo el disfrute posesorio -entendido en una acepción amplia-, que 
corresponde al contenido hipotético de la titularidad del derecho que la inscripción pública, exista o no en la realidad.

A ello se llega a partir del propio precepto legal, el artículo 41, interpretado a la luz de sus precedentes y en coherencia con el sustrato que a partir de los mismos se ha ido creando y en el que se sustenta el resto de la regulación relativa a esta acción.

A la vista del referido contenido de la acción real registral, hay que destacar que, en consecuencia, no se podrá pretender, ni obtener, por medio de ella ningún tipo de declaración sobre la real existencia o contenido de los derechos publicados en el Registro, ni se podrá solicitar la adopción de decisiones que obliguen, previamente, a realizar tales declaraciones. Tampoco se podrá impugnar o rectificar mediante esta acción la inscripción del derecho en el Registro.

\section{LEGITIMACIÓN}

Veremos, a continuación, al extenso tema de la legitimación, tanto activa, como pasiva, en el ejercicio de la acción real registral, comenzando por la primera.

\subsection{Legitimación activa}

Según se deduce del artículo 41 de la Ley Hipotecaria, está legitimado para ejercer la acción real registral el titular registral del derecho sobre el inmueble, a quien le bastará con acreditar por medio de certificación del registrador la vigencia, sin contradicción alguna, del asiento correspondiente. Esta afirmación tan evidente a la luz del citado precepto esconde numerosos problemas y cuestiones, que hacen preciso un estudio desglosado de la misma.

Para empezar, nos detendremos brevemente en la idea clave de que quien tiene la legitimación es el titular registral. Esta acción se basa en la inscripción, no deriva de un derecho real, ni de una presunción posesoria, sino de la inscripción registral. De ahí que corresponda su ejercicio a quien haya inscrito su derecho real y por el mero hecho de haberlo inscrito. Resulta indiferente si la titularidad tabular coincide o no con la titularidad real. Como sabemos, lo publicado en el Registro, aunque es tendencialmente exacto, y existe una presunción de exactitud, que, precisamente, se halla en la base de esta acción, puede apartarse, no obstante, de la realidad jurídica. Todo ello puede llevar a la situación de que no pueda ejercitar esta acción un titular real, o auténtico, del derecho, si no lo ha inscrito, o no consta en ese momento en el Registro como titular, y que, sin embargo, sí pueda ejercitarla quien no sea titular real, pero tenga inscrito el derecho a su favor. Podría, incluso, pensarse en el caso extremo de ejercicio de la acción del artículo 41 por el no propietario real, pero sí titular tabular, contra el auténtico propietario, no inscrito.

Cuando no existe un solo titular registral del derecho sobre la cosa, sino que nos encontramos ante una situación de cotitularidad registral, se deberá aplicar la doctrina general relativa al ejercicio de acciones en situación de cotitularidad y considerar que cualquier comunero está legitimado para ejercitar la acción real 
registral en beneficio de la comunidad tabular, sin necesidad de que intervengan los demás.

Ahora bien, si el titular inscrito lo es tan sólo de una cuota indivisa, sin que estén inscritas las demás, no creo que pueda ejercitar la acción real registral, porque, entonces el Registro no publica la íntegra titularidad del derecho del que deriva la pretensión real que se ejercita. No existiría una cotitularidad registral, sino tan sólo una cotitularidad jurídica, que no legitima para ejercer la acción real registral, al no haber tenido acceso al Registro. Recuérdese que lo que busca esta acción es hacer coincidir la realidad de hecho con el Registro, no con la realidad jurídica.

Estamos viendo que la legitimación activa recae en los titulares registrales de los derechos, pero cabe preguntarse: ¿de qué derechos?

Si antes de la Ley de Enjuiciamiento Civil de 2000 parecía bastante evidente que la respuesta era los derechos reales, puesto que aunque el artículo 41 de la Ley Hipotecaria hablaba sólo de "derechos inscritos", incluía una interesante referencia a "las acciones reales" procedentes de los derechos; después de dicha ley no cabe duda de ello, en cuanto que el legislador se refiere de forma clara y expresa, en el artículo 250.1.7º a los "derechos reales".

Ahora bien, conviene matizar que no toda inscripción de derecho real legitima a su titular para el ejercicio de la acción real registral, así se deriva del propio contenido y finalidad de la acción. Si se trata de una acción de integración o efectuación posesoria, en el sentido de hacer efectivo el disfrute posesorio que corresponde al contenido hipotético de la titularidad del derecho que la inscripción publica, sólo aquellos derechos reales que incluyan en su contenido un disfrute posesorio del inmueble, entendido éste en un sentido amplio, podrán dar lugar con su inscripción al ejercicio, en su caso, de la acción real registral.

Tales derechos, cada uno con sus particularidades, son: el de propiedad, usufructo, uso y habitación, superficie, censo, anticresis, servidumbre y aprovechamiento por turno de inmuebles de uso turístico (cuando se constituya como derecho real).

En el caso de las servidumbres, plantea alguna duda la inclusión en el ámbito del artículo 41 de las negativas. Y es que, mientras en las positivas, el dueño del predio sirviente tiene la obligación de dejar hacer algo al titular del derecho, o dueño del predio dominante, - o de hacerlo por sí mismo-, lo cual implica una correlativa posibilidad de actuación sobre la cosa por parte de su titular activo, que extrae de ella cierta utilidad; en las negativas, sin embargo, no existe esa posibilidad de actuación, en cuanto que se caracterizan por prohibir al dueño del predio sirviente hacer algo que le sería lícito si no existiese la servidumbre, es decir, producen para él la desaparición de una de sus facultades sobre la cosa. La ausencia de una relación posesoria o de un contacto con la cosa en estas últimas podría llevar a pensar en su exclusión. Pero, como ya he apuntado, el concepto de posesión ha de entenderse en un sentido amplio. Algún autor habla, además de posesión, de "cuasiposesión o, al menos, injerencia negativa en un fundo". Y las servidumbres negativas, en cuanto que suponen un servicio por parte del predio sirviente, entrañan injeren- 
cia o dominación fáctica sobre ese predio, que puede ser objeto de perturbación o despojo. En el caso, por ejemplo, de la servidumbre de luces, con apertura de huecos en pared propia, la prohibición que tiene el propietario del predio sirviente de tapar los huecos levantando una pared, constituye una injerencia negativa en ese fundo por parte del titular del derecho real, que se verá perturbada si se eleva un muro que tape los huecos. De manera que quien figure en el Registro de la Propiedad como titular de la servidumbre podrá ejercitar la acción real registral para que se le restituya en la dominación fáctica sobre el fundo sirviente que le corresponde en atención a lo publicado en el Registro.

En cuanto a los derechos reales que quedan excluidos del ámbito de la acción real registral, por no incluir en su contenido un disfrute posesorio -insisto, entendido en sentido amplio- $y$, por tanto, no comportar pretensiones de efectuación posesoria, hay que mencionar a los derechos reales de adquisición preferente y a la hipoteca.

En alguna ocasión se ha planteado que quizás la hipoteca puede entrar en la órbita del artículo 41 de la Ley Hipotecaria cuando el acreedor obtenga la administración y posesión interina del inmueble hipotecado, pero también se ha reconocido que entonces la hipoteca actúa en funciones de derecho anticrético. Por mi parte, me parece dudoso que pueda reconocerse en tal caso al acreedor una legitimación para ejercer la acción real registral derivada del derecho real de hipoteca, dado que tal legitimación se afirma, sin más, al advertir que existe una situación posesoria, pero hay que tener en cuenta que esa realidad posesoria no forma parte del contenido del derecho de hipoteca, es decir, no es una de las facultades que conforman ese derecho, y, por tanto, no se podrá reclamar con base en el mismo, sino que es tan sólo una fase del procedimiento de ejecución del bien, ejecución que es en sí la esencia y contenido del derecho real.

Cabe preguntarse qué sucede con los derechos de carácter personal que tienen también acceso al Registro, y señaladamente con el arrendamiento, ¿puede pensarse que su inscripción legitima al titular registral para ejercitar la acción real registral?

Me inclino por una respuesta negativa. La ley -como se ha visto- es clara al respecto: se refiere expresamente a los "derechos reales inscritos", sin incluir excepción alguna. Nótese que la acción real registral, en coherencia con las notas de inmediatez y absolutividad que caracterizan a los derechos reales, permite a quien figura en el Registro como titular del derecho, defender, directamente, y sin necesidad de que medie nadie, frente a cualquiera, la facultad posesoria que forma parte del contenido de ese derecho. El arrendamiento carece de tales caracteres; y la inscripción no cambia su naturaleza: se concedió su acceso al Registro tan sólo en orden a su subsistencia en los casos de enajenación. No creo, por otro lado, que quepa basar el ejercicio de esta acción en el artículo 1560 del Código Civil, dado que éste sólo faculta al arrendador para defender la mera posesión de hecho, con base, precisamente, en esa misma posesión fáctica que el arrendador viene ejerciendo, es decir, le atribuye una acción posesoria, basada en la posesión; y la 
acción real registral, lejos, como se sabe, de ser una acción posesoria, tiene como objetivo reintegrar la situación posesoria que forma parte del contenido del derecho publicado en favor del actor. El arrendatario para proteger el uso y disfrute como parte o contenido de su derecho, precisa del arrendador -arts. 1554.3 y 1559 CC-; no puede él defender ese contenido de su derecho publicado, directamente, y frente a cualquiera, como lo podría hacer el titular de un derecho real.

Hemos visto que pueden ejercitar la acción real registral los titulares registrales de los derechos inscritos. Acabamos de ver qué derechos quedan dentro del ámbito del artículo 41 y queda ahora detenerse en la publicación en el Registro, para determinar qué asientos pueden contener dichos derechos y las características que deben reunir.

Comenzando por los asientos que pueden contener dichos derechos, hay que apuntar que el que el artículo 41 comience hablando de derechos "inscritos" no implica que la legitimación haya de restringirse a los publicados por los asientos de inscripción: así se deduce del propio artículo 41 en su segunda parte y del hecho de que la exactitud del Registro y la legitimación registral no se limiten únicamente a la inscripción registral. Ello significa que se deberá admitir cualquier asiento que publique la titularidad actual de derechos susceptibles de integración posesoria. Veamos pues, aparte de la inscripción, qué asientos permiten tal posibilidad:

A) Empezaré por analizar las anotaciones preventivas, y en concreto, (i) el supuesto comprendido en el número 9 del artículo 42 de la Ley Hipotecaria, que se refiere a la anotación en los casos en que se presente en el Registro un título cuya inscripción no pueda hacerse por falta de algún requisito subsanable o por imposibilidad del Registrador.

No cabe ejercitar la acción amparándose en la anotación preventiva de un título que no pudo inscribirse por falta de algún requisito, aunque sea subsanable, en cuanto que, hasta que no se subsane, cosa que podrá ocurrir o no, no existirá una titularidad registral, sino sólo la probabilidad de su existencia y la advertencia de ello, la reserva de un rango, y la aplicación retroactiva de efectos. Piénsese que esta anotación es una suerte de prolongación del asiento de presentación, que caduca a los sesenta días. Podría alegarse, en relación con la aludida aplicación retroactiva de efectos, que una vez subsanado el defecto y convertida la anotación en inscripción, el titular registral lo será con efectos retroactivos, pero también es cierto que sólo lo será a los efectos posibles, y no creo que quepa incluir la legitimación para ejercer la acción real registral: téngase en cuenta que esta acción tiene como fin, no el reconocimiento de un derecho o de una situación atemporal, sino un acto muy concreto y tangible, una reintegración posesoria, que no tiene aplicación retroactiva.

Tampoco creo que quepa ejercitar la acción real registral amparándose en la anotación preventiva efectuada por imposibilidad de inscribir del Registrador debida a la presentación simultánea de títulos contradictorios, puesto que no existe tampoco ninguna titularidad registral de derecho. 
Ahora bien, diferente es que no se llegue a practicar la inscripción por causas que no afectan al título, como pueden ser: ausencia de índices o destrucción del Registro. En tales casos, el Registro sí llega a publicar una titularidad, en el primer caso, incluso, sin sujeción al plazo de caducidad del artículo 86, pero advirtiendo de una posible inexactitud debido a la imposibilidad de consultar los índices o a la destrucción del Registro. De ahí que no vea inconveniente en que quien figura como titular en esos términos solicite la reintegración de la posesión que, en principio, le corresponde.

ii) La legitimación para ejercitar la acción real registral en los supuestos de anotación preventiva del derecho hereditario, prevista en el número 6 del artículo 42 de la Ley Hipotecaria, cuando sea a favor de todos los herederos, en cuanto que la anotación del derecho hereditario publica una titularidad actual que comporta posesión (art. 440 CC), aunque en una particular situación de indivisión -de tipo germánico-.

iii) No es admisible la legitimación en el supuesto de anotación preventiva de legado, comprendida en el número 7 del artículo 42, ya que, si bien es cierto que el legatario tiene la propiedad desde la muerte del causante (art. 882.1 CC), no tiene la posesión (art. $885 \mathrm{CC}$ ), y cuando llegue el momento de la entrega, será también momento de cancelar la anotación.

iv) El resto de las anotaciones preventivas no ofrecen demasiadas dudas: no hay problema en admitir que quedan al margen de la acción real registral, dado que no publican la titularidad actual de derechos susceptibles de integración posesoria. Piénsese en las anotaciones preventivas de demanda, de embargo, de créditos refaccionarios, de prohibición de enajenar.

B) En cuanto a las notas marginales, creo que cuando éstas se presentan como notas sucedáneas de asientos principales, que tienen la eficacia del asiento al que sustituyen, hay que admitir la legitimación para el ejercicio de la acción, siempre, claro, que la nota publique un derecho real que comporte cierta dominación fáctica.

C) Resta, por último, excluir, como resulta obvio, a los asientos de presentación y de cancelación y a las menciones registrales.

Pues bien, vistos los asientos que pueden contener los derechos, veamos ahora qué características deben reunir tales asientos. Para ello debemos partir del artículo 41 que establece que se exigirá "siempre que por certificación del registrador se acredite la vigencia, sin contradicción alguna, del asiento correspondiente”. Sin dicha certificación, que ha de ser literal, no se admitirá a trámite la demanda; así lo dispone el artículo 439.2.3 de la Ley de Enjuiciamiento Civil.

En cuanto a la vigencia del asiento, que figura como primera característica, cabe destacar que el hecho de que el artículo 207 de la Ley Hipotecaria regule la suspensión de efectos, durante dos años, de la inmatriculación efectuada conforme a los artículos 205 y 206, no implica que dicha inmatriculación impida el ejercicio de la acción real registral aunque no hayan transcurrido todavía dos años, puesto que -como mayoritariamente se entiende- la limitación del artículo 207 se refiere al principio de fe pública registral, no al de legitimación. 
La inscripción deja de estar en vigor y, por tanto, no podrá servir para fundamentar la legitimación activa, cuando se inscriba la transferencia del dominio o del correspondiente derecho real a favor de otra persona. Lo mismo cuando se haya practicado un asiento de cancelación, en cuanto que ésta elimina la vigencia jurídica actual de la inscripción y presume extinguido el derecho, de forma que, aunque éste continúe existiendo, no podrá su titular -que ya no será titular tabular- utilizar el artículo 41. Y tampoco el asiento caducado podrá servir para legitimar para el ejercicio de la acción, y ello, aunque no esté cancelado, dado que la caducidad opera ipso iure.

Si la primera característica es la vigencia, la segunda es la ausencia de contradicción. Requisito este que, tal como está regulado por la ley, es fuente de problemas.

Así, se discute si la existencia de una anotación preventiva de demanda constituye contradicción que impide el ejercicio de la acción. Hay quien defiende una respuesta negativa alegando que la contradicción es a la vigencia del asiento. Y, ciertamente, si la contradicción fuese a la vigencia, la anotación de demanda no constituiría contradicción, pues la inscripción seguiría vigente. Pero creo que no estamos ante una contradicción en la vigencia, sino ante una contradicción del derecho que se publica en el asiento. Hablar de contradicción de vigencia no añade nada a exigir que el asiento esté vigente. El sentido de la ausencia de contradicción que se exige va más allá: la ley atendiendo al carácter de mera presunción iuris tantum de la exactitud del Registro, permite la indagación, si no sobre la titularidad real o material, sí sobre la existencia de datos en el propio Registro de los que deriva el carácter discutido o litigioso, y en todo caso no incontrovertible, de la titularidad en virtud de la cual se acciona. Ello implica que la anotación de demanda, cuando anuncie que la titularidad real o material tal vez pertenezca a persona distinta del titular registral, de modo que el derecho que el asiento publica y en virtud del cual se acciona no es incontrovertido, hay "contradicción" a efectos del artículo 41.

Admitida, pues, la posibilidad de que la anotación preventiva de demanda puede constituir contradicción, veamos los supuestos en que puede darse. Existirá contradicción cuando en la demanda que se anote se ejercite una acción contradictoria del dominio de inmuebles o derechos reales inscritos a nombre de quien pretende ejercitar la acción real registral y, a la vez, se entable demanda de nulidad o cancelación de la inscripción correspondiente; cuando en la demanda que se anote se ejercite la mera acción de rectificación del Registro, con perjuicio del asiento del actual titular inscrito; o cuando la acción que se anote tenga por objeto el acceso al Registro del dominio o de otra relación jurídica inmobiliaria que no conste en él, siempre que la titularidad posible anunciada por la anotación contradiga la de quien pretende ejercitar la acción real registral.

Aparte de la anotación preventiva de demanda, constituyen contradicción también la existencia de nota marginal expresiva de doble inmatriculación de la finca; la existencia de un asiento de presentación de un título, pendiente de despacho, que haya de producir la ineficacia o extinción de la inscripción vigente; así 
como la práctica de una anotación preventiva de suspensión de la inscripción de un título tal, por defecto subsanable.

\subsection{Legitimación pasiva}

En cuanto a la legitimación pasiva, unas breves palabras para pasar enseguida al estudio de las posibilidades de defensa que, precisamente, tiene el demandado.

Está legitimado pasivamente quien atente contra la situación posesoria propia del derecho publicado (situación posesoria entendida, como se sabe, en sentido amplio). El legislador suele referirse a ese atentado utilizando términos como oposición, perturbación o despojo. Quizás, podría reconducirse lo que quiere expresar con ellos a dos conceptos recopilatorios y más precisos: impedir y perturbar. El primero viene a indicar, con carácter general, que el titular registral no posee, debido a que quien posee es el demandado, haya mediado o no despojo. Y el segundo implica que el titular registral sí posee pero es inquietado en su posesión, entendiendo por perturbación cualquier lesión que no implique despojo.

El sujeto que efectúe el atentado en los términos vistos no deberá tener ningún título inscrito que resulte suficiente para legitimar sus actos, aunque existan a su favor otras inscripciones relacionadas con el bien en cuestión.

\section{Defensa del Demandado: CaUsas de oposición}

Para finalizar el estudio de la acción real registral, queda referirse a la posibilidad de defensa que tiene el supuesto perturbador. Hay que recordar que en sus orígenes la protección que otorgaba la acción real registral al titular registral era absoluta, pero que después esa tendencia evolucionó, concediéndose al demandado esta posibilidad de defensa, aunque limitándole las causas de oposición, para evitar que por esa vía perdiese eficacia el privilegio concedido al titular registral. Así, el actual artículo 444. 2 de la Ley de Enjuiciamiento Civil regula las causas tasadas de oposición que antes figuraban en el artículo 41 de la Ley Hipotecaria, y que pasamos a estudiar.

La primera causa de oposición prevista en el citado artículo es: "falsedad de la certificación del Registro u omisión en ella de derechos o condiciones inscritas, que desvirtúen la acción ejercitada".

Por lo que respecta a la falsedad en la certificación, existirá cuando haya falta de concordancia entre la certificación y la inscripción en que se funde la acción, bien por error del registrador, bien como consecuencia de una actuación de tipo delictivo de éste. Entiendo que también podrán incluirse dentro de esa expresión falsedad de la certificación los supuestos de certificación falsificada, o fingida, por el propio demandante o por un tercero, es decir, los casos en que se elabora por personas ajenas al Registro, en cuanto que no deja de haber falsedad. Lo que queda al margen de esta causa de oposición son los casos en que la falta de concordancia, sea entre la inscripción, es decir, entre el Registro, y la realidad jurídica extrarregistral, esto es, los supuestos de inexactitud registral. 
Y en relación con la omisión en la certificación de derechos o condiciones inscritos, se trata de casos en que, aun no habiendo falsedad, es decir, aun coincidiendo la certificación con el asiento, esa certificación es incompleta. Podrá darse este supuesto de hecho, por ejemplo, cuando el asiento en el que se base la acción real registral hubiese caducado, ya sea antes de emitirse la certificación, ya sea después; cuando después de expedida la certificación cambie el contenido del Registro al practicarse asientos que nieguen la legitimación activa del actor; cuando, por la razón que sea, no haga constar en la certificación la existencia de un asiento de presentación o de una anotación preventiva de suspensión que afecten a la legitimación del demandante, o si lo que no se hace constar es la existencia de una anotación preventiva de demanda que contradiga el derecho publicado.

El número 2 del artículo 444.2 de la Ley de Enjuiciamiento Civil regula como segunda causa de oposición la posesión del demandado con título o en virtud de prescripción.

Examinemos las dos posibilidades que se presentan, comenzando por la primera. En concreto, el precepto señala "poseer el demandado la finca o disfrutar el derecho discutido por contrato u otra cualquier relación juridica directa con el último titular o con titulares anteriores".

Se ha criticado la imprecisión de la expresión "por contrato u otra cualquier relación jurídica”, pero creo que, a pesar de la posible inexactitud de los términos, se atisba con facilidad su sentido. Entiendo que la ley permite oponerse al que posee como consecuencia de una relación jurídica, que lleva implícito el derecho a poseer, y que ha podido tener su origen, bien en un contrato, bien en otra fuente -la ley u otro acto jurídico-. Es decir, permite oponerse al que posee con título, entendiendo, en última instancia, como tal, la razón de adquisición de un derecho con ius possidendi. Ello significa que podrá oponerse tanto quien tenga un título de dominio o de cualquier otro derecho real que lleve consigo posesión, como quien lo tenga de derecho personal -el arrendatario, comodatario, etc.-.

Si el derecho real con base en el cual posee el demandado está inscrito, la oposición encuentra mejor fundamento en las causas primera -ya vista-y tercera -a la que enseguida aludiré-, quedando esta segunda causa como la idónea para oponerse cuando el derecho no está inscrito.

Ahora bien, al tratarse de derechos inscribibles y no inscritos surge el problema del artículo 319 de la Ley Hipotecaria, según el cual "los Juzgados y Tribunales ordinarios y especiales [...] no admitirán ningún documento o escritura de que no se hay a tomado razón en el Registro por los cuales se constituyan, reconozcan, transmitan, modifiquen o extingan derechos reales sujetos a inscripción, si el objeto de la presentación fuere hacer efectivo, en perjuicio de tercero, un derecho que debió ser inscrito".

Si bien, podría caerse en la posibilidad de negar la oposición en estos casos, no creo, sin embargo, que pueda aplicarse este precepto aquí.

Nótese que no se pretende hacer valer, ni hacer efectivo procesalmente un derecho real, apoyándose en el documento no inscrito; sino que se trata de causa 
de oposición que impide, al menos provisionalmente, que deba despojarse de su situación posesoria quien la alega, sin que ello suponga ninguna declaración del derecho a su favor. Además, ello no implica, en principio, "perjuicio a tercero", en cuanto que, más que causar perjuicio, de lo que se trata es de defenderse de una actuación perjudicial del titular inscrito.

Pero es que, aunque se considerase que sí se da el supuesto de hecho del precepto en cuestión, creo que tampoco podría aplicarse, porque el artículo 444.2 constituiría una excepción al mismo; lo contrario implicaría una contradicción del legislador.

Continuando con el examen de esta causa, hay que apuntar que aunque la ley se refiere a una vinculación "directa" con el último titular o con titulares anteriores, no parece que quepa negar la oposición a quien posea justificadamente, con un título o razón jurídica, que, aunque no fue obtenido en primer término del último o anteriores titulares, derive de quien traiga causa de aquél o aquéllos -por ejemplo, el subarrendatario-, ya que no es ese el sentido y finalidad del precepto. Con la expresión "relación directa" lo que se pretende únicamente es reforzar la idea de enlace o conexión con el titular.

Cuando el título provenga de un "titular anterior" puede plantearse el problema si el titular registral accionante es un tercero del artículo 34 de la Ley Hipotecaria.

Cabe cuestionarse qué sucede cuando el demandado sea un poseedor con título otorgado por un titular anterior y se dé la circunstancia de que el titular registral que ejercita la acción reúne los requisitos que el artículo 34 exige para la protección de la fe pública registral. ¿Tendrá o no aplicación este precepto -así como el art. 32-? Recuerdo que el mencionado artículo 34 dispone que "el tercero que de buena fe adquiera a título oneroso algún derecho de persona que en el Registro aparezca con facultades para transmitirlo, será mantenido en su adquisición, una vez que haya inscrito su derecho, aunque después se anule o resuelva el del otorgante por virtud de causas que no consten en el mismo Registro".

Creo que, con independencia de otros argumentos, para desentrañar reflexivamente la real relación entre ambos preceptos, se debe tener en cuenta el alcance y esencia de la acción real registral. Y partiendo de ello se observa cómo la posible oposición prevista en el artículo 444 de la Ley de Enjuiciamiento Civil no atenta, como a primera vista pueda imaginarse, contra el artículo 34 de la Ley Hipotecaria, al moverse en órbitas distintas. y es que no debe olvidarse que con la formulación de oposición del demandado no se discute la condición de titular del demandante, que sería el tercero del artículo 34, ni se pretende modificar el Registro al respecto, todo lo cual es ajeno a este procedimiento, sino que solamente se alega una posesión con título para evitar, según dispone la ley, un lanzamiento del inmueble por medios rápidos; es decir, se invoca el título únicamente a los efectos de paralizar la modificación de la situación posesoria del demandado, sin detrimento alguno del derecho del titular, que podrá ser invocado siempre en juicio ordinario.

Si la primera posibilidad que contempla el número 2 del artículo 444.2 es que el demandado posea con título, la segunda es que posea en virtud de prescripción. 
Ello significa que cuando el demandado haya adquirido por usucapión el dominio o un derecho real limitado que contradiga la pretensión del titular registral, podrá oponer la posesión que estos derechos comportan a la demanda ex artículo 41 ejercitada en su contra, y ello tanto si el titular registral no es tercero del artículo 34 de la Ley Hipotecaria, como si lo es, dado que el artículo 444 lo único que exige es que la prescripción "deba perjudicar al titular inscrito", lo cual puede suceder, según el artículo 36 de la Ley Hipotecaria, en ambos casos.

Bien, dejando ya los supuestos del número 2 del artículo 444.2, analizaré brevemente, a las causas previstas en los números 3 y 4 , que resultan menos problemáticas.

El número 3 establece una causa de oposición que parece estar prevista, fundamentalmente, para los casos de doble inmatriculación; se refiere a "que la finca o el derecho se encuentren inscritos a favor del demandado y asi lo justifique presentando certificación del Registro de la Propiedad acreditativa de la vigencia de la inscripción".

Y el número 4 establece como última causa de oposición del demandado el "no ser la finca inscrita la que efectivamente posea el demandado". Se trata de una cuestión de identidad de la finca. No podrá prosperar la acción real registral, basada en lo que el Registro publica en relación con un inmueble, y tendente a adaptar la realidad al Registro mediante la reintegración posesoria de dicho inmueble, si la perturbación no recae sobre él. 